\title{
Performativity and the Power of Shame: Lesson Observations, Emotional Labour and Professional Habitus
}

\author{
by Ursula Edgington \\ University of Waikato
}

Sociological Research Online, 21 (1), 11

$<$ http://www.socresonline.org.uk/21/1/11.html>

DOI: $10.5153 /$ sro.3802

Received: 8 Feb 2014 | Accepted: 28 Aug 2015 I Published: 28 Feb 2016

\begin{abstract}
Teaching and learning observations (henceforth 'observations') are used in educational environments worldwide to assess teaching quality and support professional development through reflexivity. Pressures from neo-liberalist, New Right politics encourage observations that are evaluative in nature, thereby over-emphasising quantitative strategies. Research suggests some observations are ineffectual because of emotional tensions between what is perceived as 'authentic' teaching and the inherent performativity required by managerialist policies (Ball 2003). But as Scheff (2003) argues, conformity to social processes is not necessarily based on an individual's awareness of explicit rewards or sanctions resulting from judgements. Instead it can be based on invisible self-perceptions of the risk of shame. In turn, this discourages playfulness as these actions may be considered deviations from 'best practice'. Hence observations can limit teacher effectiveness because they involve interpretations and judgements by an Other (Price 2001). This article draws on narrative data from tertiary-sector staff in a UK research study using a multi-disciplinary interpretive framework (Denzin 1989). Given the importance attributed to reflexivity in teaching practice, research in this area is sparse. Emotional factors within these contexts are often disregarded, perhaps because articulating feelings is considered weak or dangerous (Lupton 1998). However, Bourdieu's theoretical concepts of professional habitus, field and capital bring deeper meaning to interpretations of teachers' embodied emotional labour (Colley 2006a; Nias 1996; Reay 2004). The subtle nuance within the participants' narratives illuminates the observer/observee dynamic within the classroom, providing examples of the complex, fluid nature of perceptions of performativity in observations; the inherent rewards and risks.
\end{abstract}

Keywords: Psychosocial, Performativity, Emotional Labour, Bourdieu, Interpretive, Shame, Teaching and Learning, Observations, professional habitus

\section{Structure and overview of this article}

1.1 In this article, I begin with a summary of the methodology of the research study upon which it is based. In order to provide context to this article, I provide a brief explanation of observations as a managerial strategy within the global socio-economic educational setting. After explaining the context of the initial research study, the concepts of emotional labour[1] and embodied performativity within teaching and learning are explored. Links are made between these concepts and the relationships and experiences that partly form socially-constructed meanings of performativity in teaching. More specifically, elements of social and cultural capital, professional backgrounds, experience, fears and aspirations can simultaneously be un/articulated and un/conscious elements which James and Biesta (2007) term professional habitus (Bourdieu 1991). These conceptual tools illuminate how the emotional experiences of staff involved in observations are entwined with values and beliefs, past/present learning experiences and relationships; real and imagined (James and Biesta 2007). This can play a part in creating an ambiguity between individuals' unique perceptions of their identity and their performativity within the classroom. 
pressures of the perceived requirements to conform to the role of either observer/observee. One important factor in these emotional tensions appeared to be the fear of shame (Mollon 2002; Scheff 2003). Research in this area is scarce, but this relatively small-scale study provides grounds for further research to investigate this important aspect of the relational nature of emotional aspects within teaching practice.

\section{Methodology of the Research}

2.1 To summarise the methodology for this study; the fourteen participants consisted of a diverse mix of experienced, qualified staff from six geographically and socio-economically varied UK Further Education institutions (FE) [2]. The seven teachers and seven managers were based in (for example) faculties of education, engineering and health and volunteered to engage in in-depth semi-biographical interviews which were semistructured around their emotional experiences of lesson observations. Although the relatively small sample size and the potential participant bias were factors of consideration as potential weaknesses in the study outcomes, the objectives were not to achieve validation or saturation, nor to claim any generalisations about the emotional experiences of FE staff involved in observations. Rather, it was to gain some insights into the relational nature of individuals' unique emotional experiences during these situations and their perception of the inherent performativity. Full detail of the methodology for this research study is available elsewhere (Edgington 2015, 2013).

2.2 All participants (managers and teachers) had previously experienced their lessons being observed as part of institutional policies. Seven participants (managers) had also engaged in lesson observations as an observer (after receiving appropriate training and mentoring). After the interviews, transcripts were verified with each participant and fully anonymised. The narratives were analysed using an holistic, thematic strategy outlined by Ochberg (2002). Recording individuals' stories, transcribing, analysing and interpreting these for common and diverging themes has proved an effective way of creating new interpretations of emotional experiences (Charmaz 2008; Ochberg 2002).

2.3 I begin with a brief outline of the global socio-economic context of managerial teaching assessment strategies such as observations. The emotions of the individuals involved in the performativity explored in this article are unavoidably entwined within these contexts.

\section{Lesson observations policies in a global context}

3.1 Educational environments worldwide are under pressure from New Right, neo-liberalist politics which increasingly emphasise the marketisation and commercialisation of institutions through various measureable outcomes (Benade 2012; Peters 2011). Tensions are inevitable when the ideology of learning as intrinsically emancipatory collides with an accountability agenda that attempts to generate arbitrary connections between learning outcomes and teacher effectiveness (Ball and Youdell 2008; Coffield and Edward 2009; Skourdoumbis and Gale 2013). One important strategy that attempts to measure teacher effectiveness is formally-graded lesson observations which are used in educational environments worldwide to measure and improve quality and support professional development (O'Leary 2013a). However, these types of embodied surveillance strategies could be viewed as reductionist by decontextualizing learning and deprofessionalising staff by assessing only the externally observable (O'Leary 2013b).

3.2 Lesson observation policies in the UK are often annual processes that aim to fulfil public-sector funding requirements by complying with demands for accountability and transparency from stakeholders and inspectorates for self-assessment reports (O'Leary 2013c; Page 2014). Importantly, quantitative statistics derived from these measurements are perceived to have significance and to be comparable and controllable between teachers, departments, institutions and over time. Burdens from the global economic recession (bringing risks of redundancies) contribute to an audit culture that emphasises performativity because of perceived efficiency savings achieved through competition from privatisation and marketisation (Ball and Youdell, 2008). This can be demoralising for educationalists, who, as I explain, may value their role for the hidden, personal rewards it offers.

3.3 Graded outcomes from observations emphasises an underlying unhelpful binary divide in the language used in education, which draws subjective distinctions between 'success' and 'failure' - regardless of the interrelatedness of the micro and macro contexts. Understandably, this approach can heighten emotional tensions for individuals. Indeed, research from the UK and US suggests the intrinsic evaluative nature of some observation policies is often bureaucratic and punitive in nature, creating stress and anxiety for staff (Darling-Hammond 2014; O'Leary, 2012). Pressure from research and recent media publicity of this issue has led the UK government body Ofsted[3] to announce changes to some of its observation guidelines Pfsted 2014; Vaughan 2014). However the 
potential impact of these modifications upon FE-sector managerial policies remains unclear.

Whilst I acknowledge the need for a type of quality control and developmental audit procedure, there also needs to be consideration of the complexities involved. For example, individuals have differing perceptions of the specific type of performativity required of them during an observation and the potential emotional consequences. This article presents data that helps illuminate interpretations of performativity and the emotional tensions involved. It explores the emotional experiences described by FE staff involved in formally-graded observation processes.

\section{The context of the research}

4.1 The accountability agenda in education is deeply embedded within the UK FE sector, and has been for some decades (Avis 2005). It therefore presents a valuable example in the study of performativity within this context because struggle and conflict is evident between the needs of management to adhere to pressures from economic and political quarters, versus the creative hidden nature of teaching and learning (James and Diment 2003). Performativity in this setting then, is defined as the embodiment of emotional labour involved in explicitly evidencing external criteria for the purposes of conforming to this accountability agenda (Ball 2003; Whitehead 2005).

4.2 Consisting of over four-hundred post-compulsory (tertiary) institutions, the UK FE sector included approximately three million students enrolled, of all ages (Arnett 2013). FE students engage in diverse types of courses which, to varying degrees, may be defined as academic and vocational in nature, in a wide range of disciplines. The broad range of students - and the appropriate staff and processes to support them - is integral to the complexities of managing such a service. It has been argued this educational sector has suffered neglect in terms of investment from government (Ainley and Bailey 1997) prompting Randle and Brady (1997) to famously refer to FE as the 'Cinderella service'.

4.3 Changing sociological attitudes and economic pressures during the 1980's encouraged many UK individuals who wanted a 'second chance' to re-visit educational opportunities (Randle and Brady 1997). By the end of 1980, the majority of FE students were mature part-timers (Huddleston and Unwin 1997). This is important because many staff within FE have themselves benefited from FE provision - as mature students and/or within vocational or initial teachers' training (ITT) (e.g. Bathmaker and Avis 2005). It is therefore interesting to note how interpretations of some of the participants' views presented later in this article articulate the connections between memories of a student identity with current vocational and professional teaching identities at the same institution.

4.4 Throughout the 1990's the era of 'new managerialism' in the UK forced institutions to strive towards better efficiency. Often this was through the increased use of perceived scientific, quantitative approaches to measuring and controlling workforce output through Key Performance Indicators (KPIs). Policies evolved from these contexts that aimed to measure 'successful learning' via KPIs which assessed teaching competences. As Skourdoumbis and Gale (2013) and Peters (2011) point out, this issue has since evolved into a global political debate.

4.5 With the introduction of a more managerial approach, driven by terminologies and criteria defined by Ofsted, performativity became the focus in FE (Avis 1996). Lesson observation policies in particular created tensions in the form of an implicit judgement through a formally-graded assessment (O'Leary 2013c). Hence lesson observations can arguably be seen as symbolic of embodied tensions between educational policies that force management to be seen as responsive to economic and political pressures, versus the autonomous, creative and hidden nature of teaching and learning (James and Biesta 2007; McQueen 2014; Palmer 1998). FE staff in particular may value the autonomy and spontaneity of their roles that is founded on professional isolation and scarce resources in this 'Cinderella service' (Cockburn 2005). This is reflected in teachers' perceptions of how their work - in every sector - is not wholly measureable but is founded on creative empathy and intuitive artistry (Colley 2006b; Nias 1996; Schön 1991; Whitehead 2005).

\section{Capital, field and the power of performativity}

5.1 Researchers such as Nias (1996) argue that teaching involves a unique type of emotional labour ${ }^{[4]}$ due to the complex relationships between students and teacher. Because of these complex relationships, a multidisciplinary, psychosocial approach is helpful in providing meaningful analysis (Bantock 1967; Denzin 1989). The conceptual tools of Bourdieu, which contain influences from social-constructionism and existentialism, provide valuable ways of deepening understanding of these matters (Reay 2004; Zembylas 2007). For instance, 
emotional tensions have been argued to partly be a result of power-relationships between observer and observee. O'Leary (2013b) describes the impact on individuals when it is perceived that a particular type of emotional labour is required in 'performing' an observation. This unique aspect of teaching practice has a performativity that is arguably different to 'everyday' teaching practice, because it is interpreted and judged by an Other (a manager and/or experienced teacher, rather than a student or self) (Cockburn 2005; Page 2011).

Typically, the observer is trained to conduct an observation and offer a judgement of teaching and learning quality/competence based on their interpretation of 'best practice' (see Coffield and Edward 2009). The outcome from an observation, then, effectively provides an opportunity to gain or lose advantage through the reaffirming or degrading of professional status (O'Leary 2013c; Shortland 2004). Bourdieu's term 'capital' describes how an advantage of this kind is viewed as a gain (or loss) that an individual may use or accrue during his/her lifecourse. Importantly, this capital could be interpreted as a level of power between individuals in that (for example) a higher level of expertise (cultural capital) may provide benefits over others, especially as the processes may change over time.

This struggle for capital takes place within different 'fields'; boundaries of which define a social space within which an individual may exploit their social, professional and cultural capital (Swartz 1997, p. 123). This marketised environment or 'game' consists of inherent inequalities with opportunities to gain financial reward, or something more personal or altruistic, for example recognition (James and Biesta 2007; McQueen 2014). Hence, within the field of an observation, capital might be interpreted as the skills and knowledge that an observer has (or perceived to have) compared to the performativity of the teacher. There may also be benefits for a 'successfully' observed teacher in terms of promotion and/or kudos. In order to obtain professional capital then, the teacher may need to know about any written and 'unwritten' rules of the field, as well as possessing specific skills in the performativity required to explicitly evidence the pedagogical skills outlined in the criteria of the observation.

5.4 Difficulties are raised however through research that suggests those perceived as 'successful' teachers (defined differently by different people over time, for different reasons) use improvisation in their classrooms to bring new meanings to educational theory and make it their own. From this perspective, teaching practice becomes performance-based evidence for 'ever-evolving and transforming selves' (Sumara and Luce-Kapler 1996) where adding new ideas, spontaneously trying out new approaches in different contexts begins to ritualise the process of reflexivity and therefore enhancing learning becomes its own reward. This is an important and subtle aspect of professional capital because of its personal and unquantifiable nature. Arguably, it is this process (rather than a 'snapshot' of criterion-based assessment performance) which becomes the essence of the ongoing nature of learning teaching (Palmer 1998).

5.5 But improvisation, by its very nature is difficult to evaluate, elucidate or sometimes interpret or repeat (Tharp 2007). As Wacquant (2011) observes 'often practical mastery operates beneath the level of consciousness and discourse' (Wacquant 2011, p. 86). And herein lies the impossible task of the observer of teaching and learning; through seeking 'objectivity' the observer has no knowledge of (or is required to temporarily ignore) the emotional context or internalised reflexivity, but is nevertheless obliged to formally, critically analyse the performativity of the teacher. In beginning to unpack these complexities then; how and why does this performativity differ from 'everyday' teaching practice?

5.6 The classroom space in which an observation takes place may hold complex meanings that are integral to reflections upon performativity for that individual. For example, Mike, a manager of an English language department (regularly engaged in observations of his staff), acknowledged the personal nature of these spaces:

'[...] the space we occupy in the classroom is, is very private to us and our learners, you know, those four walls, it's our professional space and [if] someone's coming in and making judgements on those...' (Mike, a manager)

5.7 This indicates how the embodied presence of the observer within the classroom can fundamentally change the way teachers perceive their space - the field within which they perform the emotional labour of teaching and learning. This may be because the existing relationships between teacher and students involve complex personal understandings of each other's contexts; contexts that may be sensitive to exposure to another's presence. These private understandings were viewed by many participants as intrinsic to the personal reward within teaching; a core part of their motivation and professional identity. As explained by Jennifer, a manager (who engaged in teaching alongside observations of her staffs' teaching): 
Some observation policies are positive; teachers may enjoy the opportunity to perform their skills and engage in collaborative development of their pedagogy. But as I explain, for others, affective reactions to a perceived managerial intrusion (either embodied or via surveillance) into their professional space can have a negative impact on their well-being and teaching practice. The performativity of an observed lesson then may differ from everyday teaching practice because of its apparent 'inauthentic'[6] nature: the perceived capital to be gained/lost by staff differs between the two situations. Research in this area draws on Foucauldian perspectives arguing how intrinsic power relationships between observer/observee means articulating reflections after an observation may be problematic (O'Leary 2013c; Page 2014). This is why the psychoanalytical perspectives from Bourdieu's writings, becomes valuable, because professional dialogue can be difficult in situations that bring uncomfortable associations or memories of past judgements of in/competency (Edgington 2013). Indeed, if professional dialogue is absent, the opportunity for learning about teaching practice for observer/observee can be lost. Yet, if reflective practice is a fundamental part of continuing professional development it is crucial that it includes the emotions involved in performing.

\title{
Emotional labour: using Bourdieu's concepts of habitus and field
}

6.1 Rather than the dualistic definition that initially gave it life as a concept of debate, this article uses a broader interpretation of the term emotional labour. As defined by Hochschild (1983), emotional labour was initially founded on service-sector workers and has weaknesses when compared to the complexities of the performativity found in teaching (Nias 1996). There is no space here to re-visit these important arguments, however it is vital to note how the term emotional labour (and 'emotion work') has been open to different interpretations (e.g. Mackenzie 2011). Exploring the deeper meanings of emotional experiences means a multidisciplinary approach is required, hence Bourdieu's conceptual tools are valuable for this analysis because his poststructural, interpretive lens (Burke 2011). This provides a synthesis of philosophical, sociological, psychoanalytical, political and linguistic perspectives (Calhoun 1993; Crossley 2001; Swartz 1997). This interconnectedness across paradigms is essential to interpretations of emotional labour, as this quote illustrates:

\begin{abstract}
[...] a basic dimension of the sense of social orientation is a practical way of experiencing and expressing one's own sense of social value. One's relationship to the social world and to one's proper place in it, is never more clearly expressed than in the space and time one feels entitled to take from others; more precisely, in the space one claims with one's body in physical space, through a bearing and gestures that are self-assured or reserved, expansive or constricted and with one's speech in time, through the interaction time one appropriates and the self-assured or aggressive, careless or unconscious way one appropriates it. (Bourdieu 1984, p. 474 my emphasis)
\end{abstract}

In this quote, Bourdieu hints at the complexities of emotional labour as a route of seeking 'one's proper place in the social world'. Our sense of identity is tied-up with tensions within our performativity in striving for different types of capital, including recognition (McQueen 2014; Reay 2004). The past choices, experiences, hopes and expectations that we bring with us to every situation and relationship and which interact together, form what Bourdieu called habitus and provides an opportunity for action, or operationalizing capital. Therefore (Bourdieu argues) the human mind may at times be 'trapped' by the limits of our socialised subjectivity - in this context, arguably the socially-constructed view of what 'good teaching' is.

6.3 The body is both situated within the social world as well as the social world being intrinsic to it. On micro and macro levels, these different fields could be conceptualised at institutional or classroom layers - each with specific rules or doxa. Hence the concept of habitus is reliant upon the changing fields in which these processes exist. For instance, if some behaviours are outside the cultural norm then this may limit agency, and equally may provide opportunity for recognition through professional values (Reay 2004). Thus, when reflecting upon the interactions between the observer and observee, an awareness of the important elements of each other's habitus could be beneficial because it allows and promotes an opportunity for a deeper understanding of personal motivations and aspirations. Without this opportunity, the potential anxiety of performativity may force individuals to ignore or neglect important, contextualising aspects of habitus. Being prescriptive or punitive in approach can diminish opportunities for staff to be reflexive about teaching practices (O'Leary 2013b; Whitehead 2005, p. 18).

6.4 Bourdieu's concept of dispositions within habitus recognises the ambiguousness between the perceptions of performativity in our interactions which is founded on a lie to an Other and that which is a lie to the self (Scheff 2003). This perspective provides a deeper meaning to earlier social-constructionists' conceptualisations of performativity, who observed how at times an actor must attempt to understand how others 
perceive him by 'becoming his own audience' (Goffman 1959:86). It is this act of reflection to and by the self which Cooley (1922) theorised as 'the looking-glass self' which was developed by writers such as Scheff 2003) and Mollon (2002) and identified as a driving force for interactions. This is because in attempting to interpret how others see us, we are vulnerable to perhaps the most powerful of emotions: the potential fear of shame. Hence, part of the emotional tension in the performativity of an observation could be interpreted as being the fluid nature of pressures to conform to the social processes of what is perceived as an 'inauthentic' self (an inner lie) compared to cognizant agency to gain cultural and professional capital.

With these dramaturgical debates in mind, it is interesting to note how in this quote from a teacherparticipant (who had no managerial responsibilities) she compared her 'everyday' teaching to the emotional labour within an observation:

\footnotetext{
'You, you don't feel like you're being your actual self. [...] You feel even more like you're putting on a performance, you are kind of doing that with the students anyway, to a certain extent. [But] when someone else is watching you, it just...I don't know... it kind of makes you more self-conscious about what you are doing.' (Sam, teacher, original emphasis)
}

6.6 Sam is articulating her feelings about experiencing the subtle differences in her own performativity, compared with when her manager is observing her. Importantly she appears to divide these two different kinds of 'performances'. The phrase 'you feel even more like you're putting on a performance', defines her acknowledgement of her unique teaching identity. By being aware of 'being more self-conscious' during an observation, Sam illustrates the reflective nature of this performativity and hints at emotional consequences. All of the seven teacher-participants in this study explicitly described their feelings of anxiety about observation processes. This quote from Alex (again, a teacher without managerial responsibilities) provides one very typical example of the anxieties described:

'It was terrible. Looking back on that, [...] People were throwing-up! And being ill and like me crashing the car... because I was thinking about that [observation]. You know, it's still a huge amount of pressure, an unnecessary amount of pressure and it's unfair, being judged on your whole performance on fifty minutes once a year. It's just ridiculous. Definitely. But you still see people walking up and down the corridor, crapping themselves still, really working themselves up into a frenzy.' (Alex, teacher)

6.7 The emotions Alex describes could be interpreted as the pressures teachers may feel to perform a specific kind of emotional labour, compared to perceptions of the arguably innate nature of the performativity of their everyday teaching practice. As I explained above, pressures from external authorities often mean observation carries an implicit judgement about competence from management, in a formally-graded assessment (O'Leary 2012). This element of judgement is explained below by Jennifer, a teacher-educator with managerial responsibilities which included auditing the observation process at her institution:

\footnotetext{
'[observations] upsets people, you know people have a nervous breakdown, go off for weeks at a time, you know, we have a certain....we know.[...] People don't [...] like being watched do they, they don't like being judged. I don't think, I think people can get used to being watched, I think, it doesn't bother me too much, because I've done, I've been watched, lots, you know, but um, it's that thought of being judged, isn't it, and of course that's part of the difficulty...' (Jennifer, manager, original emphasis)
}

6.8 Because concepts of competence and integrity are intrinsically linked, the association between surveillance of teaching practice and being seen as a novice (by the self and/or an Other), as 'unprofessional' or even 'incompetent', understandably can lead to feelings of anxiety in the potential for shame (Cockburn 2005; Page 2014). Importantly, these risks exist not only on an individual level, but on an institutional level. 'Failure' may lead to a perception of professional humiliation as a result of damage to reputation, rigorous re-assessment, reduced funding and eventually closure. This supports Scheff's (2003) theory that shame forms a fundamental part of individuals' behaviour in conforming to policies that could be interpreted as strategies of social control.

6.9 At times the teacher's performativity during an observation may lead them to over-emphasise an interest in the subject area, or enthusiasm for an (over-familiar) assignment task. By comparison, the teaching may involve a subject area that the teacher has a personal and perhaps particularly emotional attachment with, the details of which they may not want to share with students. This play between emphasis and concealment may mean that - temporarily at least - certain emotions are (physically) hidden in order to preserve the self (Mollon 2002). It may be unclear to the observee to what extent this emotional labour is valued, respected, or even acknowledged by an observer. Salzberger-Wittenberg et al (1983) point out how teachers endure potential vulnerabilities to significant criticisms from their students - for example in terms of their academic ability, appearance or behaviours. It follows then, that a self-awareness and tolerance is crucial during further (closer) 
6.10 A broader definition of the concept of emotional labour raises questions about the criteria within an observation. For instance, despite its potential rewards does a teacher in a lesson observation feel it necessary (or appropriate) to 'display' any personal reward, explicitly? In contrast to being what Goffman (1959) called a 'cynical' actor, does an observer feel they need to look for evidence of a 'genuine' self? How does this 'play out' in the classroom? For example, a teacher, during an observation, may remember a conscious awareness of not being aware of the presence of the observer. That is not to say that the teacher forgets they are being observed only that their own, embodied performance becomes the (only) conscious reality of that lived moment (or rather, the memory of it). The quote below from Alex illustrates the complex nature of attempting to define this interplay of emotional consciousness:

'I wasn't anywhere near as comfortable as I would normally be (...) but I did forget they were there, but they were still at the back of my mind, still, you know...' (Alex, Teacher, my emphasis)

6.11 This slippage between an un/conscious acknowledgement of the presence of the body of an Other was a common theme within the narratives. It exposes the potential for emotional tensions between expectations of the self in the performativity and the embodied reactions to that performativity. The reflection below from Anna (a part-time teacher, with no managerial responsibilities) also illuminates the emotions that surround these dynamics:

'[...] but she [the observer] sat there, look..., frowning, you know with this real frowny, stern expression on her face... and I thought, why are you sitting there looking like that? That's making me feel really uncomfortable. So I just sort of felt that I was just losing it, because I couldn't, be myself, with this woman with this stern, frowny expression on her face. [...] I kept losing my thread and not being able to follow-up what they said? Because I just felt so utterly uncomfortable, in this stupid, stupid situation...' (Anna, Teacher, original emphasis)

6.12 This apparent interconnectedness between the perceived need for an altered state of embodied performativity was also acknowledged by a manager, Jennifer, who described a memorable emotional situation at the very beginning of her teaching career (prior to her becoming a manager which now restricts her teaching role). Her sister enrolled on a course she was teaching. She recalled her feelings during a particular observed lesson when her sister was also present:

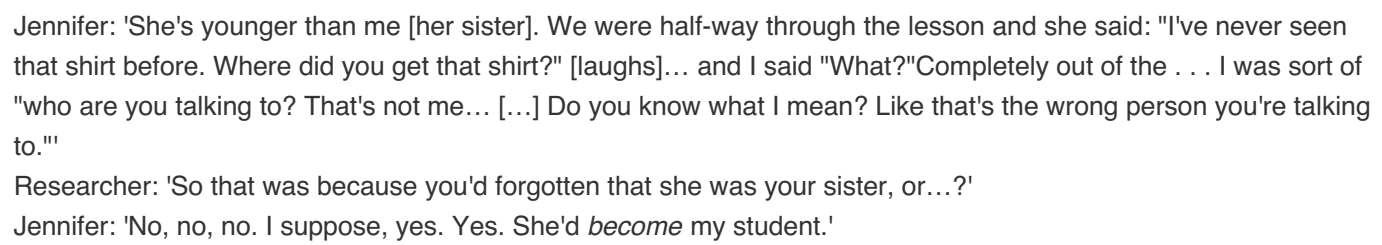

6.13 Jennifer's recollection illustrates the fluidity of her perceived performativity within this observation. Her different identities and interactions in her relationship with her sister/student touch upon her own (at that time) student-teacher identity. This again questions the perceived nature of the 'in/authentic' performativity in an observation and the changing 'angles' of emotional atmospheres (Ahmed 2012). Interpretations of these narratives present performativity in this context as complex and fluid in meaning. The following section explores some of the possible reasons for these perceptions in the different performativity in observations.

\section{Fear of shame: a powerful tool}

7.1 A teacher's performance in an observation may hold wider, symbolic implications for different fields, for example in the reputation of the department or the institution. The emotion of shame has a circular nature; we may carry shame at being ashamed and shame is felt in the body as a reaction to the previous feelings of shame (Mollon 2002; Scheff 2003). The experience of seeing ourselves as an object of the Other - here specifically as a 'good' or 'bad' teacher - inevitably produces exposure because of its potential impact upon relationships and professional habitus.

\footnotetext{
'And I know that ninety-eight percent of the people there [colleagues in the staff room] feel really badly for me, and really feel for me, but it's just that two percent of people who are just laughing at their sleeves and really pleased that I got a 'three [7]'.[...]. If I get another bloody 'three' [...] they're not going to think it was a fluke, the first time it was just a bad group, they're going to be thinking... and questioning me as a teacher.' (Alex, original emphasis)
} 
recognises the potential loss of her professional capital. This was important to Alex who valued the collegiality of her staff room because as Ahmed (2012) argues, in contrast to shame, emotions such as happiness are closely associated with social interactions. Crucially, vulnerability comes out of what the Other sees in us as inherently unknowable, even if it is partly mis/interpreted through imaginings or embodied facial expressions such as those described by Anna as 'frowny'.

7.3 As explained by Mike in his comment about the 'four walls' of professional space, the perspective of any observer includes their own prior experiences of being observed. This may raise awareness of the potential emotional anxiety in the performativity; in particular, the conflict this may present to an individual's perception of their professional identity (O'Leary 2012; Page 2014). Often an intrinsic part of the training required to be undertaken by observers involves consideration of these sensitivities, by providing feedback which contributes positively to both parties' reflections on the session. However, no matter how sensitively handled, the complexity of relationships is such that feedback can sometimes (perhaps understandably) trigger personal defence mechanisms which may inhibit an open professional dialogue (Cockburn 2005).

7.4 The perceived desirability of neglecting the emotions and seeking validity or 'objectivity' in observation procedures lies in stark contrast to the narratives of many of the participants of the research reported in this article. In keeping with other educational research, they recounted how the interactive, emotional nature of teaching and learning is a crucial factor in continuing their teaching career. As Price (2001) explains, the role of the teacher is to emotionally identify with students' experience of 'not-knowing' and it is this element that was referred to by the participants as the rewarding aspect of their role:

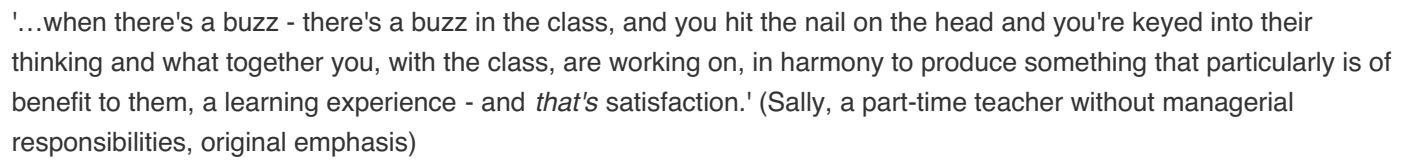

7.5 This factor seems particularly relevant in FE, where students have a 'second chance' at education. Furthermore, the teacher's autonomy within these (often wordless) interactions is integral to the emotional processes of meaning-making within (and outside) the classroom. Excluding these emotional factors in observation policies is therefore limiting to the development of the staff involved.

The positive emotional rewards teachers expressed about pride in their profession contrasted sharply with reflections of emotions surrounding observations which included fear of a risk of humiliation through shame. The behavioural impact of shame is often described in a withdrawal or covering of the body; the removal of the self from the social space or the 'publicly identified other' (Garfinkel 1956). Phrases such as "I could have sunk to the floor" and "I wanted the earth to open-up and swallow me" (Garfinkel 1956:421) resonate with participants' descriptions about wanting to 'disappear' from view after what they perceived was an 'unsuccessful' observation. They described a sense of rejection of further contact with the social world in feelings of disgust of the self. From a traditional psychoanalytic perspective, rejection is a result of attempts at protecting the ego from further pain and anxiety; this makes shame unique in that it is an emotion experienced alone and in an individual's own time. This is partly why it is argued to be a powerful tool in processes of social control (Scheff 2003), including educational environments (Benade 2015; Vardi 2012).

7.7 In line with this view of shame, Sally described her memory of her emotions after a particularly challenging exchange with her manager after an observation. She described how she "just closed down" to cope with these feelings - a phrase which illustrates a view of herself as a machine unable to function. This notion of rejection was also important in the narrative of Alex:

\footnotetext{
'...who knows what the complex reasons might be, but when I got that 'three [8]', I was absolutely, erm, devastated, and I cried uncontrollably... And I had to go home...And that's never happened to me before [...], I just went in the toilet [to cry], and I just think it was, er, to me it was, I think I was working so very hard...' (Alex)
}

7.8 In this profoundly heartfelt quote, Alex describes her emotional experience of an observation. She explains her shame at what she interpreted as her self being reflected as a failure, contrasted against her pride and professional identity. The tensions between the support necessary during this emotional experience and the perceived socially 'acceptable' behaviour of being seen/unseen was evident in the teacher, Naima's comments below:

'I wouldn't like to express that childishness in front of my peers and so I wouldn't cry. I just keep it inside me, I wouldn't cry, just hold it inside me. [...]. But like, Tuesday [the day of the observation] I was really like holding it in, I 
felt 'God, I need a cry after this' After the observation I just go to the Ladies [toilets] and just cry to relieve myself. Just let it out.' (Naima, teacher with no managerial responsibilities)

There are echoes here with the narrative of Alex in how she felt isolated from colleagues who were apparently 'laughing at the sleeves' over this event, rather than supporting her. However, as I explained earlier there is sometimes not a clear distinction between the self that feels emotion and the bodily response to emotions (Dunlop 1984). There are complex connections in our un/conscious selves from past, present and future experiences, fears and aspirations which feed into these emotions (Denzin 1984). "Shame emerges at moments of our deepest psychological vulnerability" (Mollon 2002:26). This is because these embodied emotions are deeply connected to our past relationships and experiences - real and imagined - thus the complex hidden nature of teachers' professional habitus (Crossley 2001; James and Diment 2003).

7.10 In comparison to the negative impact of the emotions described by Naima and Alex, in a later interview, Alex explained the value and importance of a shared trust and empathy with a colleague; supporting views of the importance of sharing emotional experiences (Ahmed 2012). A mentor opportunity provided the space for her to articulate feelings about the performativity that was required of her for a follow-up observation:

'...that you've got links into [a mentor] that does actually take the time and you don't feel rushed and you can actually do, what you can do to improve yourself. And, and something that's very real and realistic and things to improve the situation that I don't really feel was there before.' (Alex)

7.11 Being given the opportunity to openly discuss the emotional labour of her teaching was seen by Alex and other participants as beneficial in itself (either in the workplace or through participating in the research, or both). However, the consequences of these positive relationships between teachers and mentors had wider implications for some difficult relationships with colleagues:

'I've got my revenge on them, yeah, [...], but you know, it's about - I've got this 'one[9]', basically because I had time to prepare that I didn't have before and I've also had support and input from the [mentor], which has been fabulous.' (Alex, teacher)

7.12 Hence as can be seen in the change in Alex's narrative, the power of shame is immense, both positively and negatively: 'feelings of weakness, helplessness and passivity associated with shame - can lead to a wish to turn the tables and triumph over the other, giving rise to feelings of guilt' (Mollon 2002:29). This comment from Mollon illuminates Alex's remarks above, which show the joy at her perceived 'revenge' after the negative comments she received from some colleagues after the initial observation experience. Again this illustrates the changing field of observations within which complexities in relationships and individuals' motivations can impact upon the emotional experiences and performativity.

\section{The performativity of the observers}

8.1 The seven managers (including Jennifer referred to above) in the research reported here were (to varying degrees) also engaged in teaching. This added a further dimension to their role as observer as by definition they were perceived by their staff as seeing themselves as 'experts' in teaching (even if they tried to avoid this connection); thereby possessing professional habitus which could potentially be operationalised within a field (Bourdieu 1991). This inequality of power was emphasised in the narratives because the managers often seemed to place importance on the relationships that they had with their fellow managers; providing an interesting parallel to the perspectives of the teachers who valued the rapport they built-up with their students. However, the managers also often described how much they valued their (somewhat limited) teaching time. This was perhaps understandable considering that often managers spent less time actually in the classroom (because of their other duties). In the eyes of some staff this may be seen as limiting managers' cultural capital (James and Biesta 2007). In the case of Julia and Helen (two managers from the same institution but different departments) the value they placed on this rapport was evident:

'I think that's a huge part of, of staying, you know, isn't it? The social aspect of having someone to talk to and bounce ideas off [in the management team].' (Helen)

And:

'It's very [inaudible] females feel not quite good enough, constantly and I think if you don't have some kind of support that will say: 'Well, actually, I feel like that as well, it's been a nightmare and that you couldn't do it is understandable' - I would feel constantly not quite good enough, because we do not celebrate fully ... we pick on anything that goes wrong' (Julia) 
pick on anything that goes wrong' if she also acknowledges the negative impact this may have on her staff members. Some possible reasons for this perceived lack of agency are explored below. However, the positive impact of the support between members of the management team forms a contrast to the experiences of conflict and fear of shame from the teachers' experiences of observations. Nevertheless, there was also a recurrent theme from the managers' narratives of a strength of feeling and support for their staff and a sense of respect for their skills and commitment to teaching. For example, Jason, a senior manager in a language department, related his experience of observing a teacher from a different faculty: he enthusiastically described how he had witnessed a 'gifted' teacher who he thought had innate skills in the performativity required in the explicit criteria set out in the observation requirements. He concluded with this comment:

'And the interesting thing was - the teacher wasn't aware he was doing it!' (Jason, senior manager)

8.3 This quote begs the question why Jason believed the teacher he observed was unaware of his unawareness - and how this impacted upon Jason's assessment of this teacher's performativity. What visible factors were involved? Without speaking to the observee in this specific observation, it is impossible to know to what extent he was aware of the embodied nature of his performativity; however the quotes from some of the teachers above provide clues. For instance, like Alex, he may have forgotten Jason was there, whilst retaining a sense that he was 'still at the back of my mind. This further supports the idea that rather than a dualistic concept, the emotional labour involved in the performativity of observations requires a more flexible analytical approach (Nias 1996; Reay 2004).

8.4 Narratives from other managers reflected a sense that there was a need to build rapport with their staff, whilst simultaneously (and arguably paradoxically) retain a detachment from these relationships in order to maintain appropriate 'managerial processes'. These same processes were openly acknowledged to be the cause of anxiety, stress and frustration for staff:

'....and [...] it was all about that and people were hauled over the coals and made to feel less than who they were. And you should not come to work, if you've tried your best and feel less than who you are when you leave. That's not a good thing. (Helen, manager, original emphasis)

8.5 The reasons for the managers' apparent detachment from their acknowledged contradictions in needing to build rapport with staff compared to a need for 'objectivity' in their roles could be attributed to commercial pressures at that time of budgetary constraints and impending redundancies. This links to the macro-level tensions from the global marketisation and commercialisation of education I outlined earlier. Funding cuts were imminent at the time of these interviews due to the worsening UK economic recession. This climate of fear was profoundly important to the context of the managers' narratives, as Helen went on to explain:

'They are afraid. Everyone is afraid. Everyone in a job, there aren't many jobs about I, I don't know what would happen to me personally, if I couldn't work, I have no money to speak of, erm, I like my life, I love what I do, so I think, they know that, and they know that you are hungry, if you like, that you need this job. You have to 'toe the line' whether you're happy about it or not.' (Helen, manager, original emphasis)

8.6 Interestingly, in the above quote, Helen defines her staff as 'they'; and also her senior management as 'they' - leaving her own identity (a manager) caught in-between. In contrast to this, the narrative of James, a senior manager, seemed to view the anxiety that accompanied the particular kind of emotional labour in observations as an integral part of a teacher's role. He drew parallels to a driving test that 'everyone has to endure'. With this in mind, it was interesting to note James' response to comments about the way some staff (like Mike) may perceive their classrooms as a personal space:

\footnotetext{
'... [that] would be very much an 'old school' approach, I think, because we are trying to generate an ethos here [...] where we've got a much more 'open door' approach. I mean, our [new department] development we've got glass all the way along so you can't hide behind a door. So we're trying to have a much more transparent approach...'

(James, senior manager, my emphasis).
}

8.7 In contrast from the personal nature of learning spaces defined by Mike, James appeared to dismiss the need of some teachers to create a more intimate learning atmosphere. Contrasting the views of the teacher Alex with the views of James, it is understandable how emotional tensions arise in observations. James had previously studied at the same institution where he was now a senior manager. His approach seemed contradictory; accepting the integral subjectivities of the reports based on graded observations, whilst simultaneously placing high importance on them.

\section{Conclusions}


In this article I have provided some micro and macro level factors to some of the emotional complexities within the processes of lesson observation policies. Within the contexts of the initial research study drawn upon here, I have explored the relevance of the concepts of emotional labour and embodied performativity within observations. I have used multi-disciplinary theoretical concepts from Bourdieu to show how emotional tensions between relationships and experiences are partly formed from socially-constructed meanings of performativity of teaching. More specifically, I have shown how the concepts of capital, field and professional habitus bring significance to interpretations of the narratives in explaining the interconnectedness of professional identity, experience, aspirations and fear of shame. These factors can simultaneously be present and hidden creating uncertainty between individuals' unique perceptions of their unique performativity within observation processes.

9.2 Understanding the conflict between the needs of management to adhere to the pressures from economic and political quarters, versus the creative hidden nature of the emotional labour of teaching and learning in FE is integral to the emotional tensions of teaching and in particular the performativity of observations (Ball 2003; Ball and Youdell 2008). This is arguably because rather than being developmental, observations represent for some, a symbolic representation of a 'deficit' model; an inherent risk of judgement as an 'incompetent teacher' - and the consequences this label may carry in terms of a reflection of the self. Pressures for increased accountability within educational systems drives the perceived need for quantitative evidence of assessment of teaching and learning outcomes. However current debates about observations leave little space for a deeper understanding of the how and why of individuals' lived emotional experiences (Ahmed 2012; Denzin 1984; Lupton 1998).

9.3 Concepts such as emotional labour and professional habitus help illuminate the complex and fluid nature of the emotional lived experiences within the fields of observer/observee interactions. The subtle nuance of these emotions traverse the explicit, hidden and un/conscious - concepts which form the central debates about a sociology of the emotions (Bantock 1967; Bourdieu 1991; Lupton 1998). Because of the processes and interactions between and within emotions and learning, exploring these relational experiences is crucial in creating effective yet sensitive teaching development strategies (James and Biesta 2007; Reay 2004). Research suggests how it is these affective elements of observations and their interconnectedness with more macro-level factors that deserve further investigation.

9.4 In summary, for the participants in the research presented here, there were powerful tensions between the different pressures of the perceived requirements to conform to the role of either observer/observee and their personal values and experiences. This article has only touched the surface in providing some insights into the multidimensional aspects of the emotional lived experiences of FE staff in the observation process. The importance of personal histories, motives and meanings of teaching and learning could be incorporated holistically, without being categorised under a surveillance regime. Debates could include the terminologies and definitions that surround the performativity of observations and also an acceptance of the intrinsic emotions. One important factor in these emotional situations appears to be the fear of shame (Scheff 2003) which has a complex relationship with aspects of professional habitus. Research in this area is scarce, but examples from outcomes of this relatively small-scale study provide grounds for further investigation into the emotional aspects of performativity in reflecting upon teaching practice.

\section{Notes}

The specific interpretation of how this concept is utilised in this article is explained below.

These post-compulsory tertiary colleges have a complex definition which is summarised below.

Office for Standards in Education (UK)

A problematic concept, its use in this article is defined in the following section.

UK Post-compulsory qualification in a specified subject.

I acknowledge the problematic nature of this term, but this discussion is outside the scope of this article.

Refers to a numerical grading system used by Ofsted defined at the time as a lesson which was 
'satisfactory' and later re-defined as 'requires improvement'.

See the footnote above.

A grade one is defined by Ofsted as the highest grade obtainable or 'outstanding' teaching and learning.

\section{References}

AHMED, S., (2012). Sociable Happiness, in: Dale, S., Walby, K., Hunt, A. (Eds.), Emotions Matter: A Relational Approach to Emotions. University of Toronto Press, Toronto, Canada, p. 40-62.

AINLEY, P., Bailey, B., (1997). The business of learning: staff and student experiences of Further Education in the 1990's. Cassell, London.

ARNETT, G., (2013). Further Education statistics: number of academic staff drops. The Guardian 7 Nov 2013.

AVIS, J., (2005). Beyond performativity: reflections on activist professionalism and the labour process in Further Education. Journal of Education Policy 20, p. 209-222. [doi:10.1080/0268093052000341403]

AVIS, J., (1996). The enemy within: quality and managerialism in education, in: Avis, J., Bloomer, J., et al. (Eds.), Knowledge and Nationhood: Education, Politics and Work. Cassell, New York, p. 105-120.

BALL, S.J., (2003). The teacher's soul and the terrors of performativity.Journal of Education Policy 18, p. 215228. [doi:10.1080/0268093022000043065]

BALL, S.J., Youdell, D., (2008). Hidden Privatisation in Public Education, Education International. Institute of Education, University of London, UK.

BANTOCK, G.H., (1967). Education, Culture and the Emotions. Faber and Faber, London.

BATHMAKER, A.-M., Avis, J., (2005). Becoming a lecturer in further education in England: the construction of professional identity and the role of communities of practice. Journal of Education for Teaching 31, p. 4762. [doi:10.1080/02607470500043771]

BENADE, L., (2015). Shame: Does it have a place in an education for democratic citizenship?Educational Philosophy and Theory 47, p. 661-674. doi:10.1080/00131857.2014.880644 [doi:10.1080/00131857.2014.880644]

BENADE, L., (2012). From Technicians to Teachers: ethical teaching in the context of globalised education reform. Bloomsbury Publishing, eBook.

BOURDIEU, P., (1991). Language and Symbolic Power. Polity Press, Cambridge, UK.

BOURDIEU, P., (1984). Distinction: a social critique of the judgement of taste. Harvard University, USA.

BURKE, C., (2011). The Biographical Illumination: A Bourdieusian Analysis of the Role of Theory in Educational Research. Sociological Research Online 16, 9. [doi:10.5153/sro.2325]

CALHOUN, C., (1993). Habitus, Field and Capital: the historical specificity in Bourdieu, in: Calhoun, C., LiPuma, E., Postone, M. (Eds.), Bourdieu: Critical Perspectives. London, p. 61-88.

CHARMAZ, K., (2008). Grounded Theory in the 21st Century, in: Lincoln, Y. (Ed.), Strategies for Qualitative Inquiry. Sage Publications Inc., California, USA, p. 203.

COCKBURN, J., (2005). Perspectives and Politics of Classroom Observation. Research in Post-Compulsory Education 10, p. 373-388. [doi:10.1080/13596740500200211]

COFFIELD, F., Edward, S., (2009). Rolling out "good", "best" and "excellent" practice. What next? Perfect practice? British Educational Research Journal35, p. 371-390. [doi:10.1080/01411920802044396]

COLLEY, H., (2006a). From Childcare Practitioner to FE Tutor: biography, identity and lifelong learning, in: 
Leathwood, C., Francis, B. (Eds.), Gender and Lifelong Learning: Critical Feminist Engagements. Routledge Falmer, London.

COLLEY, H., (2006b). Learning to Labour with Feeling: class, gender and emotion in childcare education and training. Contemporary Issues in Early Childhood7, p. 15-29. [doi:10.2304/ciec.2006.7.1.15]

COOLEY, C., (1922). Human Nature and the Social Order. Schribers, New York, USA.

CROSSLEY, N., (2001). The Social Body. Sage, London.

DARLING-HAMMOND, (2014). One Piece of the Whole: Teacher Evaluation as Part of a Comprehensive System for Teaching and Learning. Journal of the American Federation of Teacher Spring.

DENZIN, N.K., (1989). Interpretive Interactionism, Applied Social Research Methods Series. Sage Publications Inc., California, USA.

DENZIN, N.K., (1984). On Understanding Emotion. Jossey-Bass, London.

DUNLOP, F., (1984). The Education of Feeling and Emotion: Introductory Studies in Philosophy of Education. Allen and Unwin Ltd, London.

EDGINGTON, U., (2015). Constructing Creative Non-Fiction: Telling Teachers' Stories About Being Observed. Sage Research Methods, Case Studies. http://www.srmo.sagepub.com/view/methods-case-studies2016/n25.xml?rskey=mPfr7j\&row=77.

EDGINGTON, U., (2013). Performativity \& Affectivity: Lesson Observations in England's Further Education Colleges (PhD Unpublished Thesis). Canterbury Christ Church University, Kent, UK.

GARFINKEL, H., (1956). Conditions of Successful Degradation Ceremonies. The American Journal of Sociology 61, p. 420-424. [doi:10.1086/221800]

GOFFMAN, E., (1959). T he Presentation of Self in Everyday Life.Penguin, London.

HOCHSCHILD, A., (1983). The Managed Heart: commercialisation of human feeling. University of California Press, Berkley, CA. USA.

HUDDLESTON, P., Unwin, L., (1997). Teaching and Learning in Further Education. Routledge, London.

JAMES, D., Biesta, G., (2007). Improving Learning Cultures in Further Education. Routledge, London.

JAMES, D., Diment, K., (2003). Going underground? Learning and assessment in an ambiguous space.Journal of Vocational Education and Training 55, p. 407-422. [doi:10.1080/13636820300200237]

LUPTON, D., (1998. The Emotional Self. Sage, London.

MACKENZIE, S., (2011). "It"s been a bit of a roller-coaster': special educational needs, emotional labour and emotion work. International Journal of Inclusive Education 16, p. 1067-1082.

[doi:10.1080/13603116.2010.538869]

MCQUEEN, H., (2014). Roles, Rights and Responsibilities in UK Education: tensions and inequalities 1st ed. Palgrave MacMillan, New York, USA. [doi:10.1057/9781137390240]

MOLLON, P., (2002). Shame and Jealousy: the hidden turmoils. Karnac, Londo(n.

NIAS, J., (1996). Thinking about feeling: the emotions of teaching. Cambridge Journal of Education 26, p. 293306. [doi:10.1080/0305764960260301]

OCHBERG, R., (2002). Teaching Interpretation, in: Josselson, R., Lieblich, A., McAdams, D. (Eds.), Up Close and Personal: The Teaching and Learning of Narrative Research. American Psychological Society, Washington DC, USA, p. 101-112.

OFSTED, (2014). How do Ofsted inspectors evaluate teaching in the further education and skills sector?

O'LEARY, M., (2013a) O'Leary, M. (2013) Classroom Observation: a guide to the effective observation of teaching and learning. Abingdon, OXON: Routledge. 
O'LEARY, M., (2013b). Expansive and Restrictive approaches to professionalism in FE colleges: The observation of teaching and learning as a case in point. Research in Post-Compulsory Education 18, p. 248-364. [doi:10.1080/13596748.2013.847164]

O'LEARY, M., (2013c). Surveillance and normalised practice: The impact of graded lesson observations in Further Education Colleges. Journal of Further and Higher Education 37, p. 694-714. [doi:10.1080/0309877X.2012.684036]

O'LEARY, M., (2012). Time to turn worthless lesson observation into a powerful tool for improving teaching and learning. InTuition: Institute for Learning 9, p. 16-8.

PAGE, L., (2014). Further Education Teachers' Perceptions of Being Observed Teaching: a single institution case-study (PhD Thesis (Unpublished)). Univerity of Lincoln, UK, Lincoln, UK.

PAGE, L., (2011). Just Four Little Grades: 1,2,3 or 4?Management in Education 25, p. 93-94. [doi:10.1177/0892020610387959]

PALMER, P., (1998. The Courage to Teach: Exploring the Inner Landscape of a Teacher's Life. Jossey Bass, San Francisco.

PETERS, M., (2011). Neoliberalism and After? Education, Social Policy, and the Crisis of Western Capitalism. Peter Lang, New York, USA.

PRICE, H., (2001). Emotional labour in the classroom: a psychoanalytic perspective.Journal of Social Work Practice 15, p. 161-180. [doi:10.1080/02650530120090610]

RANDLE, K., Brady, M., (1997). Managerialism and professionalism in the "Cinderella Service."Journal of Vocational Education and Training 49, p. 121-139. [doi:10.1080/13636829700200007]

REAY, D., (2004). "It"s all becoming a habitus': beyond the habitual use of habitus in educational research. British Journal of Sociology of Education 25, p. 444. [doi:10.1080/0142569042000236934]

SALZBERGER-WITTENBERG, I., Williams, G., Osborne, E., (1983). The Emotional Experience of Learning and Teaching. Karnac Books Ltd., London. [doi:10.4324/9780203393093]

SCHEFF, T., (2003). Shame in self and society. Symbolic Interactionism 26, p. 239-262. [doi:10.1525/si.2003.26.2.239]

SCHÖN, D., (1991). The Reflexive Practitioner: how professionals think in action. Ashgate, Aldershot, UK.

SHORTLAND, S., (2004). Peer Observation: a tool for staff development or compliance? Journal of Further and Higher Education 28, p. 219-228. [doi:10.1080/0309877042000206778]

SKOURDOUMBIS, A., Gale, T., (2013). Classroom teacher effectiveness research: a conceptual critique.British Educational Research Journal39, p. 892-906. [doi:10.1002/berj.3008]

SUMARA, D., Luce-Kapler, R., (1996). (Un)Becoming a teacher: Negotiating identities while learning to teach. Canadian Journal of Education 21, p. 65-83. [doi:10.2307/1495065]

SWARTZ, D., (1997). Culture and Power: the sociology of Pierre Bourdieu.University of Chicago Press, London.

THARP, T., (2007). The Creative Habit: learn it and use it for life. Simon and Schuster, New York, USA.

VARDI, I., (2012). Developing students' referencing skills: a matter of plagiarism, punishment and morality or of learning to write critically? Higher Education Research \& Development 31, p. 921-930. [doi:10.1080/07294360.2012.673120]

VAUGHAN, R., (2014). Ofsted scraps grades for individual lessons. Times Educational Supplement.

WACQUANT, L., (2011). Habitus as Topic and Tool: Reflections on Becoming a Prizefighter.Qualitative Research in Psychology 8, 81-92. doi:10.1080/14780887.2010.544176 [doi:10.1080/14780887.2010.544176]

WHITEHEAD, S., (2005). Performativity Culture and the FE Professional.Management in Education 19, p. 1618. [doi:10.1177/08920206050190030401] 
ZEMBYLAS, M. (2007). Emotional Capital and Education: Theoretical Insights from Bourdieu British Journal of Educational Studies, 55 (4), p. 443-463. 